\title{
Ketorolac analgesia for inguinal hernia repair is not improved by peripheral administration
}

\section{[L'analgésie au kétorolac pour une herniorraphie inguinale n'est pas améliorée} par l'administration périphérique]

Kenneth J. Kardash MD, ${ }^{*}$ Jacob Garzon MD,† Ana M. Velly DDS PhD, $\ddagger$ Michael J. Tessler MD*

Purpose: It has been suggested that ketorolac, a non-steroidal antiinflammatory drug (NSAID) available for parenteral use, may result in prolonged $(24 \mathrm{hr})$ postoperative analgesia through a peripheral mechanism when added to local anesthetic infiltration. Our objective was to assess this effect by controlling for systemic absorption of the drug.

Methods: This randomized, double-blind trial studied 40 men undergoing elective inguinal hernia repair under spinal anesthesia. All patients received $19 \mathrm{~mL}$ of lidocaine $1 \%$ infiltrated in the operative field before incision. Patients were randomized into two groups of 20. The surgical site group received ketorolac $30 \mathrm{mg}$ added to the lidocaine infiltration. In the control group, ketorolac $30 \mathrm{mg}$ was injected subcutaneously in the contralateral abdominal wall. Numeric rating scores $(0-10)$ of pain at rest and with movement were recorded at the time of discharge from the recovery room and at $24 \mathrm{hr}$ postoperatively. Time to first analgesia, postoperative iv morphine use, total time in the recovery room, and total oral analgesic use in the first $24 \mathrm{hr}$ were also compared.

Results: There were no significant differences between groups with respect to any of the measured variables. In both groups, pain scores were low at rest $(1.9 \pm 1.4$ vs $2.2 \pm 1.8$, surgical site and systemic groups, respectively) and moderate with movement (5.3 $\pm 2.2,5.0 \pm 1.8)$ after anesthetic recovery. Pain scores were similar at $24 \mathrm{hr}(1.1 \pm 1.3,1.9 \pm 1.6$ at rest; $5.7 \pm 2.0,6.2 \pm 2.2$ with movement).

Conclusion: Adding ketorolac to lidocaine infiltration for hernia repair does not improve or prolong postoperative analgesia compared to systemic administration.
Objectif: On a pensé que le kétorolac, anti-inflammatoire non stéroïdien (AINS) disponible pour usage parentéral, ajouté à une infiltration d'anesthésique local, pouvait prolonger (24 h) l'analgésie postopératoire par un mécanisme périphérique. Nous voulions évaluer cet effet en vérifiant l'absorption systémique du médicament.

Méthode : Notre étude randomisée et à double insu a porté sur 40 hommes, répartis au hasard en deux groupes de 20, devant subir une herniorraphie inguinale réglée sous rachianesthésie. Tous les patients ont reçu $19 \mathrm{~mL}$ de lidocaïne à $1 \%$ par infiltration dans le champ opératoire avant l'incision. Les patients du groupe expérimental ont reçu 30 mg de kétorolac ajoutés à l'infiltration de lidocaïne. Ceux du groupe témoin ont reçu une injection sous-cutanée de $30 \mathrm{mg}$ de kétorolac dans la paroi abdominale controlatérale. Les scores numériques (0-10) de douleur au repos et pendant le mouvement ont été enregistrés au départ de la salle de réveil et 24 h après l'opération. Ont aussi été comparés le temps écoulé avant la première analgésie, l'usage de morphine iv postopératoire, le temps passé à la salle de réveil et l'analgésique oral total pendant les 24 premières heures.

Résultats : II n'y a pas eu de différences intergroupes significatives pour toutes les variables mesurées. Les scores de douleur ont été faibles au repos ( $1,9 \pm 1,4$ vs 2,2 $\pm 1,8$, pour les groupes expérimental et témoin, respectivement) et pendant un mouvement modéré $(5,3 \pm 2,2,5,0 \pm 1,8)$ après l'anesthésie. Les scores de douleur ont été similaires à $24 \mathrm{~h}(1,1 \pm 1,3,1,9 \pm 1,6$ au repos; 5,7 \pm 2,0, 6,2 \pm 2,2 au mouvement).

Conclusion : L'ajout de kétorolac à l'infiltration de lidocaïne, comparé à l'administration systémique, n'améliore pas et ne prolonge pas l'analgésie post-herniorraphie inguinale.

From the Departments of Anesthesiology, ${ }^{*}$ Surgery, $\nmid$ and Center for Clinical Epidemiology and Community Studies, $\ddagger$ Sir Mortimer B. Davis-Jewish General Hospital, McGill University, Montreal, Quebec, Canada.

Address correspondence to: Dr. Ken Kardash, Anesthesia Department, Room A335, SMBD-Jewish General Hospital, 3755 Cote Ste.

Catherine, Montreal, Quebec H3T 1E2, Canada. Phone: 514-340-8222, ext. 5701; Fax: 514-340-8108; E-mail:

kenneth.kardash@mcgill.ca

Reprints will not be available.

Accepted for publication December 1, 2004.

Revision accepted February 19, 2005. 
$\mathrm{K}$

ETOROLAC is a non-steroidal anti-inflammatory drug (NSAID) which is often given parenterally for postoperative analgesia. Laboratory research has confirmed that this analgesia is at least partially mediated through a central effect. ${ }^{1}$ However, some reports suggest a direct, peripheral mechanism of analgesia from local application at the site of injury. One study in human volunteers found local effects of ketorolac on postburn hyperalgesia. ${ }^{2}$ Enhanced postoperative analgesia was reported when ketorolac was injected intra-articularly for arthroscopic knee surgery ${ }^{3}$ or added to $i v$ regional blocks for hand surgery. ${ }^{4}$ Two studies suggest that ketorolac infiltrated into the wound during inguinal hernia repair may result in analgesic effects greater than when given systemically, persisting up to $24 \mathrm{hr}^{5,6}$ One of these trials found that ketorolac admixed with lidocaine infiltration produced a longer-lasting analgesic effect than lidocaine alone. ${ }^{6}$ These results suggested a novel route by which to administer ketorolac to achieve long-acting analgesia in outpatients.

Inguinal hernia repair continues to be one of the most painful ambulatory surgeries, with almost half of patients reporting moderate to severe pain 24 hr later. ${ }^{7}$ At our institution, outpatient hernia repair is performed routinely under spinal anesthesia with local anesthetic wound infiltration to optimize postoperative analgesia. We sought to determine if peripheral administration of ketorolac would improve analgesia in this setting. Our primary interest was to test pain relief outcomes at 24 $\mathrm{hr}$, because of the practical benefit this would have in simplifying ambulatory analgesia.

\section{Methods}

This randomized, double-blind trial was performed from February 2003 through November 2003 at a university-affiliated teaching hospital. All patients gave informed consent to the protocol approved by the Institutional Ethics Committee. Eligible patients were ASA class I or II adult males undergoing first-time, elective, unilateral inguinal hernia repair under spinal anesthesia. Exclusion criteria were: contraindications to NSAID use (allergy, ulcers, renal insufficiency, coagulopathy), refusal of or other contraindication to spinal anesthesia, allergy to amide local anesthetics, analgesic use in the preceding $24 \mathrm{hr}$, and communication barrier to pain reporting. Forty patients were invited to participate and all agreed. All operations were performed by the same surgeon (J.G.).

Patients were prospectively randomized using blocks of four into two treatment groups. In the surgical site group, $1 \mathrm{~mL}$ of ketorolac $30 \mathrm{mg} \cdot \mathrm{mL}^{-1}$ (Sabex 2002 Inc., Boucherville, QC, Canada) mixed with $19 \mathrm{~mL}$ of lidocaine $1 \%$ was infiltrated in the operative field by the surgeon before incision, and $1 \mathrm{~mL}$ of saline was injected subcutaneously in the contralateral abdominal wall. In the systemic control group, $1 \mathrm{~mL}$ of saline was mixed with the $19 \mathrm{~mL}$ of $1 \%$ lidocaine for pre-incisional infiltration, and $1 \mathrm{~mL}$ of ketorolac $30 \mathrm{mg}$ was given subcutaneously on the contralateral side. All study drugs were prepared by the pharmacy in advance in a sterile fashion and stored at room temperature until use. Ketorolac has been shown to be stable when mixed with lidocaine for at least one week at $37^{\circ} \mathrm{C} .{ }^{8}$

Intraoperatively, all patients received $i v$ normal saline. Standard anesthetic monitoring was employed. Spinal anesthesia was performed in the sitting or decubitus position at the mid-lumbar level using a 27gauge Whitacre needle. Hyperbaric bupivacaine $9 \mathrm{mg}$ with fentanyl $10 \mu \mathrm{g}$ were administered and the patient immediately laid supine. Infiltration of study drugs at the surgical site was achieved using 25-gauge Quincke-tipped spinal needles. Contralateral $1 \mathrm{~mL}$ injections were made using a 25-gauge hypodermic needle (all needles from BD Medical Systems, Franklin Lakes, NJ, USA). No opioids were given before or during surgery. At the discretion of the attending anesthesiologist, propofol in incremental doses of 20 mg was given for sedation during the procedure. Duration of surgery was defined as time from incision until arrival in the recovery room.

Postoperative pain in the recovery room was treated with morphine $2 \mathrm{mg} i v$ every five minutes $p r n$, based upon nurses' assessment. At discharge, patients received a prescription for oxycodone $5 \mathrm{mg}$ with acetaminophen $325 \mathrm{mg}$, one or two tablets every four hours prn, and were asked to record the total number of tablets taken. Arrangements were made in advance for a telephone follow-up at $24 \mathrm{hr}$. An 1l-point numeric rating scale (NRS) was used by the anesthesiologist to assess postoperative pain intensity $(0=$ none, $10=$ worst imaginable) at discharge from the recovery room and at $24 \mathrm{hr}$ postoperatively. At both time points, NRS was assessed both at rest and with movement (standing up).

The primary outcome was pain intensity with movement at $24 \mathrm{hr}$. Secondary measures of analgesia were: time to first analgesic dose (TTFA), as measured from the beginning of surgery; total dose of iv morphine administered in the recovery room; pain intensity at recovery room discharge; pain at rest at $24 \mathrm{hr}$ and total number of oral analgesic tablets used in the first 24 postoperative hours. Duration of stay in the recovery room until discharge criteria were met (pain controlled, ability to tolerate oral fluids, stand unassisted, micturate) was also recorded. The surgeon, 
TABLE I Characteristics of patient groups

\begin{tabular}{llll}
\hline Characteristics & $\begin{array}{l}\text { Ketorolac in } \\
\text { surgical site } \\
n=20\end{array}$ & $\begin{array}{l}\text { Ketorolac in } \\
\text { contralateral } \\
\text { site } n=20\end{array}$ & P value \\
\hline Age $(\mathrm{yr})$ & $57.3(12.0)$ & $55.3(16.8)$ & 0.65 \\
& $54.5(41-81)$ & $57.5(25-85)$ & \\
Weight $(\mathrm{kg})$ & $82.3(19.6)$ & $78.3(9.3)$ & 0.41 \\
& $78.5(55-145)$ & $76.5(67-107)$ & 0.30 \\
Height $(\mathrm{cm})$ & $171.2(8.0)$ & $173.8(7.7)$ & 0.30 \\
& $170(155-188)$ & $175(160-186)$ & 0.40 \\
Surgery duration $(\min )$ & $35.3(4.4)$ & $34.0(4.8)$ & 0.40 \\
& $35(30-45)$ & $35(25-45)$ & \\
\hline
\end{tabular}

For each variable, first row is mean (SD); second row is median (range).

anesthesiologists and nurses were all blinded to the study groups.

\section{Statistical analysis}

We compared study group variables during recovery room stay and at $24 \mathrm{hr}$ after surgery. Descriptive statistics were used to evaluate the characteristics of treatment groups (e.g., age, weight, height and surgery duration) and study outcomes. The results were examined with both univariate and multivariate analyses. The multivariate analysis adjusted for the putative confounding effects of age, weight, height, and duration of surgery. The difference between group means and the $95 \%$ confidence interval (CI) were calculated for each variable. The analysis of each study outcome was performed using the SAS general linear model procedure. Statistical significance was defined as $P<$ 0.05. All tests were performed using the Statistical Applications Software of the SAS Institute, version 8.2 (Cary, NC, USA).

For the sample size calculation, a significant outcome was defined as a difference between groups in mean NRS pain score with movement at $24 \mathrm{hr}$ of 1.6, with a standard deviation of 1.6. These figures were based on results of a previous study. ${ }^{6}$ Using Power and Sample Size Calculator, version 1.0.15 (Nashville, TN, USA), for an $\alpha$ of $5 \%$ and power of $80 \%$, a sample size of 40 ( $n=20 /$ group) was sufficient to find such an outcome difference, if it existed.

\section{Results}

Complete data were obtained on all patients. There were no differences between groups with respect to demographic variables or duration of surgery (Table I).

Results are summarized in Table II. At discharge and $24 \mathrm{hr}$ postoperatively, patients experienced pain that was mild at rest and moderate with movement.
The site of ketorolac administration had no significant effect on pain scores. There were no differences between groups with respect to any other outcome variables: TTFA, iv morphine consumption, time in the recovery room or oral analgesic use in the first 24 hr. After multivariate analysis to control for the possible combined confounding effects of age, weight, height, and duration of surgery, the findings were unchanged.

Two patients in each group received iv propofol sedation at the beginning of the procedure. The cumulative doses were 20 and $60 \mathrm{mg}$ in the control group and 20 and $40 \mathrm{mg}$ in the surgical site group. All patients were fully alert upon arrival in the recovery room.

One patient in the operative site ketorolac group developed a small scrotal hematoma while in the postanesthesia care unit and was admitted to hospital overnight for observation. He was discharged the next morning without requiring further intervention. No wound hematoma was observed in either group.

\section{Discussion}

We found no evidence of improved or longer-acting analgesia from the addition of ketorolac to lidocaine infiltration in inguinal hernia repair compared to a systemic dose. Methodologic improvements in the control group and sample size considerations compared to previous trials of peripheral ketorolac in hernia repair make it unlikely that these are falsely negative results.

Ben-David et al. ${ }^{5}$ found ketorolac $30 \mathrm{mg}$ intrawound as effective as infiltrating $20 \mathrm{~mL}$ bupivacaine $0.25 \%$, and more effective than $60 \mathrm{mg} i m$ in reducing pain scores during the first $24 \mathrm{hr}$ postoperatively. In that trial, infiltrations were performed at the end of surgery under general anesthesia, and there were only eight patients per treatment group, with no other analgesics administered intraoperatively. The systemic ketorolac was administered by deltoid $i m$ injection, without a placebo control. It is possible that this may have unblinded their study to recovery room observers. In a subsequent trial, ${ }^{9}$ the same investigators found no difference between intrawound, im or iv administration in analgesia $90 \mathrm{~min}$ after surgery using combined field block and general anesthesia. In that series, the systemic groups were placebo-controlled, each group contained 14 patients and infiltration was performed preoperatively with $50 \%$ more local anesthetic volume.

Connelly et al. ${ }^{6}$ studied 30 hernia repairs performed under local anesthesia using $1 \%$ lidocaine with epinephrine. They found that ketorolac $60 \mathrm{mg}$ infiltrated in the wound significantly decreased analgesic requirements 
TABLE II Postoperative outcome measures

\begin{tabular}{|c|c|c|c|c|c|c|}
\hline & \multicolumn{3}{|c|}{ Univariate analysis } & \multirow[b]{2}{*}{ P value } & \multicolumn{2}{|c|}{ Multivariate analysis* } \\
\hline & Surgical site $n=20$ & Control $n=20$ & $\begin{array}{l}\text { Between groups } \\
\text { mean difference } \\
(95 \% \text { CI })\end{array}$ & & $\begin{array}{l}\text { Between groups } \\
\text { mean difference } \\
(95 \% \mathrm{CI})\end{array}$ & P value \\
\hline \multicolumn{7}{|l|}{ Recovery room } \\
\hline \multirow[t]{2}{*}{ Pain at rest } & $1.9(1.4)$ & $2.2(1.8)$ & $0.3(-0.8,1.3)$ & 0.63 & $0.3(-0.8,1.4)$ & 0.58 \\
\hline & $2(0-7)$ & $2(0-7)$ & & & & \\
\hline \multirow[t]{2}{*}{ Pain during movement } & $5.3(2.2)$ & $5.0(1.8)$ & $-0.3(-1.6,1.0)$ & 0.64 & $-0.6(-2.0,0.8)$ & 0.37 \\
\hline & $5.5(2-9)$ & $5.0(1-8)$ & & & & \\
\hline \multirow[t]{2}{*}{ Time to first analgesia $(\mathrm{min})$} & $314.8(175.5)$ & $354.8(196.7)$ & $40.0(-79.3,159.3)$ & 0.50 & $46.1(-83.6,175.9)$ & 0.47 \\
\hline & $277.5(0-800)$ & $307.5(0-725)$ & & & & \\
\hline \multirow[t]{2}{*}{ Morphine use (mg) } & $1.6(2.4)$ & $3.0(4.0)$ & $1.4(-0.7,3.5)$ & 0.19 & $1.7(-0.6,3.9)$ & 0.14 \\
\hline & $0(0-8)$ & $1(0-14)$ & & & & \\
\hline \multirow[t]{2}{*}{ Time to discharge ( $\mathrm{min})$} & $337.0(81.5)$ & $377.0(98.3)$ & $42.0(-17.8,97.8)$ & 0.17 & $21.1(-20.3 ; 62.6)$ & 0.31 \\
\hline & $332(185-490)$ & $360(195-580)$ & & & & \\
\hline \multicolumn{7}{|l|}{$24 \mathrm{hr}$ after surgery } \\
\hline \multirow{2}{*}{ Pain at rest } & $1.1(1.3)$ & $1.9(1.6)$ & $0.7(-0.2,1.7)$ & 0.11 & $0.5(-0.5,1.4)$ & 0.33 \\
\hline & $1(0-4)$ & $2(0-6)$ & & & & \\
\hline \multirow[t]{2}{*}{ Pain during movement } & $5.7(2.0)$ & $6.2(2.2)$ & $0.5(-0.8,1.9)$ & 0.40 & $0.5(-0.9,2.0)$ & 0.44 \\
\hline & $5(3-10)$ & $6.5(2-10)$ & & & & \\
\hline \multirow{2}{*}{$\begin{array}{l}\text { Oral analgesic use } / 24 \mathrm{hr} \\
\text { (number of tablets) }\end{array}$} & $4.5(2.8)$ & $4.8(2.6)$ & $-0.3(-2.0,1.4)$ & 0.73 & $-0.1(-1.6,1.4)$ & 0.87 \\
\hline & $5(0-10)$ & $4(0-9)$ & & & & \\
\hline
\end{tabular}

$\mathrm{CI}=$ confidence interval. Pain values are numerical rating scale $(0-10)$. For each variable, first row is mean $(\mathrm{SD})$; second row is median (range). *Between groups mean difference (control - surgical site) was calculated separately in multivariate model, which included age, weight, height, and duration of surgery.

and pain on movement at $24 \mathrm{hr}$ postoperatively compared to the same dose given in a double-blind manner intravenously. However, the group receiving ketorolac injected in the wound also received significantly more supplemental lidocaine infiltration.

Intramuscular ketorolac reaches peak systemic levels almost one hour later than an $i v$ dose. ${ }^{10}$ This delay in systemic effect may have presented a significant bias to positive results when an iv control group was compared. Although ketorolac absorption kinetics from a surgical wound are unknown, we feel that a control injection in corresponding contralateral tissue provided a reasonable comparison, because of similar tissue vascularity.

The dose of ketorolac $(30 \mathrm{mg})$ evaluated in our study was half that used in one trial reporting effects at $24 \mathrm{hr},{ }^{6}$ but similar results were claimed for $30 \mathrm{mg}$ in another. ${ }^{5}$ Since these reports, the recommended parenteral dose of ketorolac for postoperative analgesia has been lowered to $30 \mathrm{mg}$ in the United States and $10 \mathrm{mg}$ in the United Kingdom. ${ }^{11}$

It has been suggested that clinical studies of analgesia require a placebo control group to accurately quantitate drug effects. ${ }^{12}$ However, ketorolac has already been shown to improve analgesia and reduce opioid requirements postoperatively when given by a variety of parenteral routes. ${ }^{3,4,13}$ Our objective was to test claims of enhanced efficacy of the same ketorolac dose when added to local anesthetic infiltration. We felt it was neither necessary nor ethical to include a placebo group, since NSAIDs are part of our routine postoperative analgesia regimen.

There is concern from the perspective of study design that the combination of spinal bupivacaine-fentanyl and local lidocaine may have produced analgesia of sufficient duration to overwhelm any effect of the ketorolac. However, the mean time to first analgesic request in our patients $(315 \pm 176 \mathrm{~min})$ was not significantly different from that of patients undergoing hernia surgery with local anesthesia and iv ketorolac $(379 \pm 177 \mathrm{~min})$ in another trial. ${ }^{6}$ In that study, as in ours, there were no differences in pain scores in the recovery room. In any case, our primary goal was to examine the effect on movement-associated pain at 24 hr reported by others. ${ }^{5,6}$ Shorter-term differences which may have existed before surgical analgesia dissipated (median of approximately five hours in both groups) are clinically moot. Only those effects beyond the immediate recovery period would confer a practical advantage to ketorolac infiltration over repeated systemic dosing. Our results are consistent with clinical experience that a single dose of ketorolac by tradi- 
tional systemic routes does not provide significant analgesia $24 \mathrm{hr}$ later. ${ }^{11}$

Local ketorolac infiltration has potential disadvantages. One is that the alcohol diluent may be irritating to tissues. ${ }^{6}$ The occurrence of a scrotal hematoma in the study group raised the concern of a local antiplatelet effect, a well-documented side effect of systemic NSAIDs. ${ }^{14}$ However, no hematomas at the site of injection were observed.

In summary, the results of our study do not disprove a peripheral mechanism of NSAID analgesia. However, our findings do suggest there is no clinical advantage to adding ketorolac to local anesthetic infiltration compared to systemic administration for postoperative analgesia.

\section{Acknowledgements}

We thank Eva Cohen and Sambho Kim of the Pharmacy department for their kind assistance in preparing the study drugs.

\section{References}

1 Malmberg $A B$, Yaksh TL. Pharmacology of the spinal action of ketorolac, morphine, ST-91, U50488H and L-PIA on the formalin test and an isobolographic analysis of the NSAID interaction. Anesthesiology 1993; 79: 270-81.

2 Lundell JC, Silverman DG, Brull SJ, et al. Reduction of postburn hyperalgesia after local injection of ketorolac in healthy volunteers. Anesthesiology 1996; 84: 502-9.

3 Reuben SS, Connelly NR. Postoperative analgesia for outpatient arthroscopic knee surgery with intraarticular bupivacaine and ketorolac. Anesth Analg 1995; 80: 1154-7.

4 Reuben SS, Steinberg RB, Kreitzer JM, Duprat KM. Intravenous regional anesthesia using lidocaine and ketorolac. Anesth Analg 1995; 81: 110-3.

5 Ben-David B, Katz E, Gaitini L, Goldik Z. Comparison of i.m. and local infiltration of ketorolac with and without local anaesthetic. Br J Anaesth 1995; 75: 409-12.

6 Connelly NR, Reuben SS, Albert M, Page D. Use of preincisional ketorolac in hernia patients: intravenous versus surgical site. Reg Anesth 1997; 22: 229-32.

7 McGrath B, Elgendy H, Chung F, Kamming D, Curti $B$, King $S$. Thirty percent of patients have moderate to severe pain $24 \mathrm{hr}$ after ambulatory surgery: a survey of 5,703 patients. Can J Anesth 2004; 51: 886-91.

8 Reinhart DJ, Stagg KS, Walker KG, et al. Postoperative analgesia after peripheral nerve block for podiatric surgery: clinical efficacy and chemical stability of lidocaine alone versus lidocaine plus ketorolac. Reg Anesth Pain Med 2000; 25: 506-13.

9 Ben-David B, Baune-Goldstein U, Goldik Z, Gaitini L.
Is preoperative ketorolac a useful adjunct to regional anesthesia for inguinal herniorraphy? Acta Anaesthesiol Scand 1996; 40: 358-63.

10 Jung D, Mroszczak E, Bynum L. Pharmacokinetics of ketorolac tromethamine in humans after intravenous, intramuscular and oral administration. Eur J Clin Pharmacol 1988; 35: 423-5.

11 Sweetman SC. Martindale. The Complete Drug Reference, 33rd ed. London: Pharmaceutical Press; 2002: 49.

12 Kalso E. Better standardisation will improve the quality of analgesic studies. Acta Anaesthesiol Scand 1996; 40: 397-8.

13 Gillies GW, Kenny GN, Bullingham RE, McArdle CS.

The morphine sparing effect of ketorolac tromethamine. A study of a new, parenteral nonsteroidal anti-inflammatory agent after abdominal surgery. Anaesthesia 1987; 42: 727-31.

14 Marret E, Flabault A, Samama CM, Bonnet F. Effects of postoperative, nonsteroidal, anti-inflammatory drugs on bleeding risk after tonsillectomy. Meta-analysis of randomized, controlled trials. Anesthesiology 2003; 98: 1497-1502. 